\title{
Frohes Fest
}

Liebe Leserin, lieber Leser,

Zeit für ein Resümee nach dem ersten Jahr ATZelektronik, in dem die Planung der Inhalte und Beiträge komplett bei mir lag. Ein spannendes Jahr, da es zugleich davon geprägt war, dass wegen Covid-19 seit März der persönliche Kontakt wegfiel: Messen, Pressekonferenzen oder auch die sonst stets persönlich geführten Interviews - auf einen Schlag perdu.

Wegen des Lockdowns waren die Sorgen in den Unternehmen vor allem in der ersten, akuten Phase nachvollziehbarerweise teils deutlich andere, als Beiträge für Zeitschriften wie die ATZelektronik zu verfassen. Insofern war oft Kreativität vonnöten, um trotz allem runde Hefte zu „fertigen“ und die Qualität des Magazins zu halten oder zu steigern. Wenn Ihnen ein Thema gefehlt hat oder Sie zukünftig mehr über bestimmte Aspekte lesen wollen, senden Sie mir eine E-Mail; gern auch einen Beitragsvorschlag.

Ein Ziel auf der Agenda ist auch die weitere Profilschärfung der ATZelektronik. Dies zeigt sich in der sorgfältig getroffenen Artikelauswahl, dank der auch Halbleiterfirmen von A wie Analog Devices über N wie NXP oder Nvidia bis hin zu T wie Texas Instruments verstärkt integriert werden: Da Fahrzeuge immer mehr zur rollenden Elektronik werden und Funktionalität immer stärker über Software definiert wird, müssen sich Fahrzeugentwickler abteilungsübergreifend intensiv mit diesen Themen beschäftigen. Es kann nicht sein, dass ein Auto mit Top-Spaltmaßen, aber fehlerbehafteter Software zum Käufer rollt auf der anderen Seite sollte (Seitenhieb beabsichtigt) in meiner Vorstellung von einer idealen Welt auch keiner ein Auto mit Top-Software, aber an etlichen Stellen bescheidener mechanischer Qualität akzeptieren müssen.
In der realen Welt funktioniert interessanterweise das zweite Geschäftsmodell außerordentlich gut; trotz Ergebnissen wie in der J. D. Power Quality and Satisfaction Study 2020 beschrieben. Geschuldet ist das wohl der Verzückung der Fans analog zu Apple in Steve Jobs' Zeiten, aber in Ordnung ist das nicht wirklich. Auf der anderen Seite treiben die Kollegen aus Palo Alto ihre Pendants in Untertürkheim, München oder Wolfsburg extrem an: Ohne Elon Musk hätte man im Auto viele Dinge noch lange nicht gesehen. Dafür kann man für eine gewisse Zeit auch hinnehmen, dass es manchmal klappert oder zieht, aber nicht auf Dauer.

Nun, lesen hilft: Was immer wir von ATZelektronik, ATZ und MTZ machen können, um Sie mit dem zur Verbesserung des ersten Geschäftsmodells nötigen Wissen zu versorgen, werden wir tun.

In diesem Sinne, wünsche ich eine friedvolle, erholsame Weihnachtszeit und einen guten Start ins neue Jahr hoffentlich bald ohne Corona. Bleiben Sie gesund!

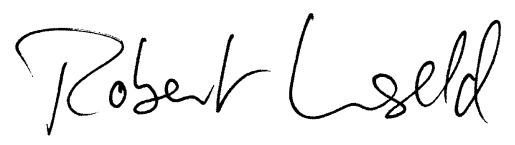

Robert Unseld

Verantwortlicher Redakteur

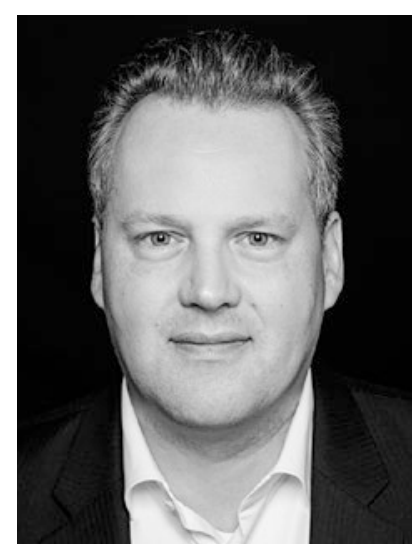

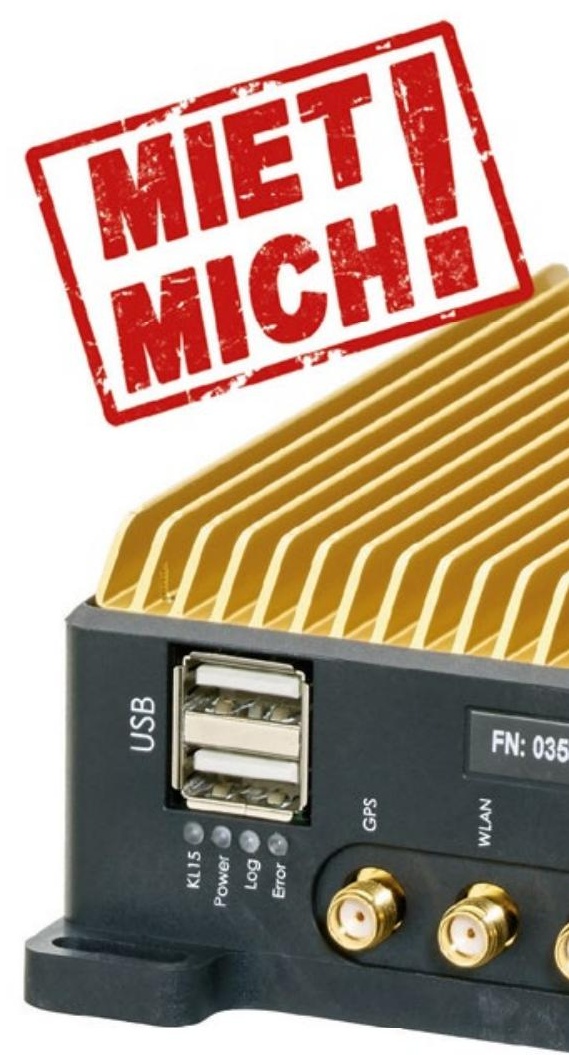

RENT A LOGGER

Das neue Mietmodell von IPETRONIK 